\title{
Dampak Sampah Plastik Bagi Ekosistem Perairan
}

\author{
Ahmad Fahrizal $^{1}$, Muhaiminah Akib ${ }^{2}$ \\ ${ }^{1,2}$ Universitas Muhammadiyah Sorong, Kota Sorong, Indonesia \\ Email : a.fahrizal.ab@gmail.com
}

\begin{abstract}
Abstrak
Tujuan pelaksanaan pengabdian kepada Siswa SMA/SMA dan SMP di Kelurahan Malagusa Distrik Aimas Kabupaten Sorong adalah untuk memberikan pengetahuan dan pemahaman kepada siswa tentang sampah dan sampah plastik, jenis-jenis sampah plastik, ekosistem perairan, dampak pembuangan sampah bagi lingkungan, serta penanggulangan sampah dan solusinya. Metode yang digunakan adalah metode ceramah dan demonstrasi bersama siswa sekolah di Kelurahanan Malagusa tentang sampah dan penanganannya. Hasil pelaksanaan pengabdian ini bahwa siswa-siswa yang bersekolah di kelurahan Malagusa adalah (1) apresiasi yang tinggi pemerintah setempat dalam hal ini pemerintah kelurahaan Malagusa mengenai kegiatan seminar yang dilaksanakan (2) motivasi tinggi peserta seminar pengabdian yang berasal dari siswa SMK, SMA, dan SMP se-kelurahan Malagusa dengan keaktifan bertanya pada sesi diskusi yang dipandu oleh panitia pelaksana kegiatan. (3) peningkatan pemahaman, pengetahuan dan kemampuan siswa dalam memahami tentang sampah dan dampak sampah bagi lingkungan perairan.
\end{abstract}

Kata Kunci: Sampah Plastik, Dampak Sampah, Ekosistem Perairan

\begin{abstract}
The purpose of the service to high school/vocational high school, and junior high school students in malagusa Village, Aimas Distric, Sorong Regency is to provide knowledge and understanding to students about waste and plastic waste, types of plastic waste, the solution ecosystem. The method used is a lecture and demonstration method with sxhool students in Kelurahan Malagusa about waste and its handling. The results of the implementation of this community service where students attending Malagusa Village were(1) appreciation of the local government in this case the Malagusa village Government in this case the Malagusa Government regarding the seminar activities carried out (2) the high motivation of the community service seminar participant coming from Vocational, high school and junior high school students the whole village of Malagusa with liveliness asking questions at the discussion session guided by the activity organizing committee. (3) Increaasing students' understanding, knowledge and ability in understanding about waste and increasing waste for the environment.
\end{abstract}

Key words: Plastic waste, Rubbish impact, Aquatic Ecosystem 


\section{Pendahuluan}

Menyandang status sebagai negara kepulauan terbesar di dunia, Indonesia memiliki panjang garis pantai $81.000 \mathrm{~km}$ dengan luas wilayah 5 juta $\mathrm{Km}^{2}$ atau 2/3 wilayahnya adalah perairan (Nontji, 2007). Potensi ini menyebabkan Indonesia menjadi negara penyumbang sampah terbesar kedua di dunia setelah Cina/Tiongkok (CNN), (Wahyuni, 2016), dikarenakan produksi sampah di Kota Besar di Indonesia mencapai $0,7 \mathrm{Kg}$ sampah/orang/hari atau sebanyak 175.000 ton sampah per hari secara nasional menurut Kementerian Lingkungan Hidup dan Kehutanan (KLHK) (Bisnis.com, 2019).

Fenomena alam belakangan ini semakin memperlihatkan kejadian yang berbeda dibanding beberapa puluh tahun lalu, yang terjadi di lingkungan sekitar baik lingkungan biotik seperti di hutan mangrove, daerah pesisir lautan dan lainlain; serta lingkungan abiotik yang meliputi air, udara, tanah, topografi, dan lain sebagainya. Kejadian tersebut ditandai dengan seringnya ditemukan kejadian berupa pencemaran air, tanah, udara dan suara/polusi yang berimbas pada maraknya kasus mamalia laut yang terdampar di kawasan perairan.

Pencemaran terhadap lingkungan dapat terjadi di mana saja dengan laju yang sangat cepat. Beban pencemaran yang semakin berat diakibatkan limbah industri dari berbagai bahan kimia termasuk logam berat atau B3 (bahan berbahaya dan beracun). Untuk mencegah terjadinya pencemaran terhadap lingkungan oleh berbagai aktivitas industri dan aktivitas manusia, maka dipandang perlu dilakukan pengendalian terhadap pencemaran lingkungan dengan menetapkan baku mutu lingkungan.

Beberapa fenomena yang terjadi berupa terdamparnya mamalia laut seperti paus, dugong, lumba-lumba yang terdampar di beberapa wilayah pesisir laut Indonesia. Salah satu contoh kasus adalah seekor dugong yang mati terdampar di Kampung Malaumkarta, Distrik Makbon, Wilayah Sorong pada senin (1/7/2019) (Darilaut.id, 2019). Fenomena terdamparnya mamalia laut tersebut disebabkan oleh beberapa faktor, salah satunya adalah gangguan navigasi karena pengaruh sonar bawah laut, polusi suara (seismic) yang mengganggu sistem navigasi, perburuan mangsa sampai ke perairan yang dangkal, karena terluka dan karena sakit (Direktorat Konservasi Kawasan dan Jenis Ikan, 2012). Hal lain yang turut mempengaruhi navigasi dari mamalia adalah gempa bumi, serta tertelannya 
sampah oleh mamalia laut sehingga membuat mamalia laut menjadi terdampar. Kejadian ini semakin sering muncul seperti seekor paus sperma ditemukan mati akibat menelan $22 \mathrm{~kg}$ sampah plastic dan terdampar di satu pantai di Porto Cervo, tujuan wisata popular di Sardinia, Italia (liputan6.com, 2019).

Maraknya berbagai fenomena tersebut menuntut kepedulian terhadap lingkungan utamanya dalam pengelolaan sampah. Sampah yang terdiri dari beberapa jenis seperti sampah organik dan non-organik seperti pasltik marak ditemukan di lingkungan kita. Sampah plastik adalah salah satu bahan yang dapat kita temui di hampir setiap barang. Mulai dari botol minum, alat makanan (sendok, garpu, wadah, gelas), kantong pembungkus/kresek, TV, kulkas, pipa pralon, plastik laminating, sikat gigi, compact disk (CD), kutex (cat kuku), mainan anak-anak, mesin, alat-alat militer hingga pestisida (Kurniastuti, 2016). Seperti PP (gelas air kemasan), HDPE (botol shampoo), PETE (botol air kemasan), Other (bungkus makanan ringan), dan sampah plastik lain.

Adapun jenis-jenis sampah plastik disajikan pada Gambar 1 dibawah ini yang biasa ditemukan adalah (1) PET/PETE - Polyethylene Terephthalate, direkomendasikan HANYA SEKALI PAKAI. (2) HDPE - High Density Polyethylene : bahan plastik yang aman, mencegah reaksi kimia antara kemasan plastik dengan makanan/minuman yang dikemasnya, memiliki sifat yang keras, buram dan lebih tahan suhu tinggi, tetapi tidak direkomendasikan dipakai berulang-ulang. (3) V/PVC - Polyvinyl Chloride, Bahan ini lebih tahan terhadap bahan senyawa kimia, minyak, dll. Dengan titik leleh 70 - $140{ }^{\circ} \mathrm{C}$. (4) LDPE Low Density Polyethylene. Dapat didaur ulang, sulit dihancurkan, tetapi tetap baik untuk tempat makanan atau minuman karena sulit bereaksi secara kimiawi dengan makanan atau minuman yang dikemas dengan bahan ini. (5) PP — Polypropylene, botol transparan yang tidak jernih atau berawan. Titik lelehnya $165^{\circ} \mathrm{C}$, Carilah dengan kode angka 5 bila membeli barang berbahan plastik, untuk menyimpan kemasan berbagai makanan dan minuman. (6) PS - Polystyrene merupakan polimer aromatik yang dapat mengeluarkan bahan styrene ke dalam makanan ketika makanan tersebut bersentuhan. Bahan ini harus dihindari, karena selain berbahaya untuk kesehatan otak, mengganggu hormon estrogen pada wanita yang berakibat pada masalah reproduksi, pertumbuhan dan sistem syaraf, juga bahan ini 
sulit didaur ulang. Bila didaur ulang, bahan ini memerlukan proses yang sangat panjang dan lama. Jika tidak tertera kode angka dibawah kemasan plastik, maka bahan ini dapat dikenali dengan cara dibakar (cara terakhir dan sebaiknya dihindari). Ketika dibakar, bahan ini akan mengeluarkan api berwarna kuningjingga, dan meninggalkan jelaga. Titik leleh pada $95^{\circ} \mathrm{C}$. (7) Other - Bahan dengan tulisan Other berarti dapat berbahan SAN - styrene acrylonitrile, ABS acrylonitrile butadiene styrene, PC - polycarbonate, Nylon. PC - polycarbonate, dapat mengeluarkan bahan utamanya yaitu Bisphenol-A ke dalam makanan dan minuman yang berpotensi merusak sistem hormon, kromosom pada ovarium, penurunan produksi sperma, dan mengubah fungsi imunitas. Dianjurkan untuk tidak dipergunakan untuk tempat makanan ataupun minuman karena Bisphenol-A dapat berpindah ke dalam minuman atau makanan jika suhunya dinaikkan karena pemanasan.

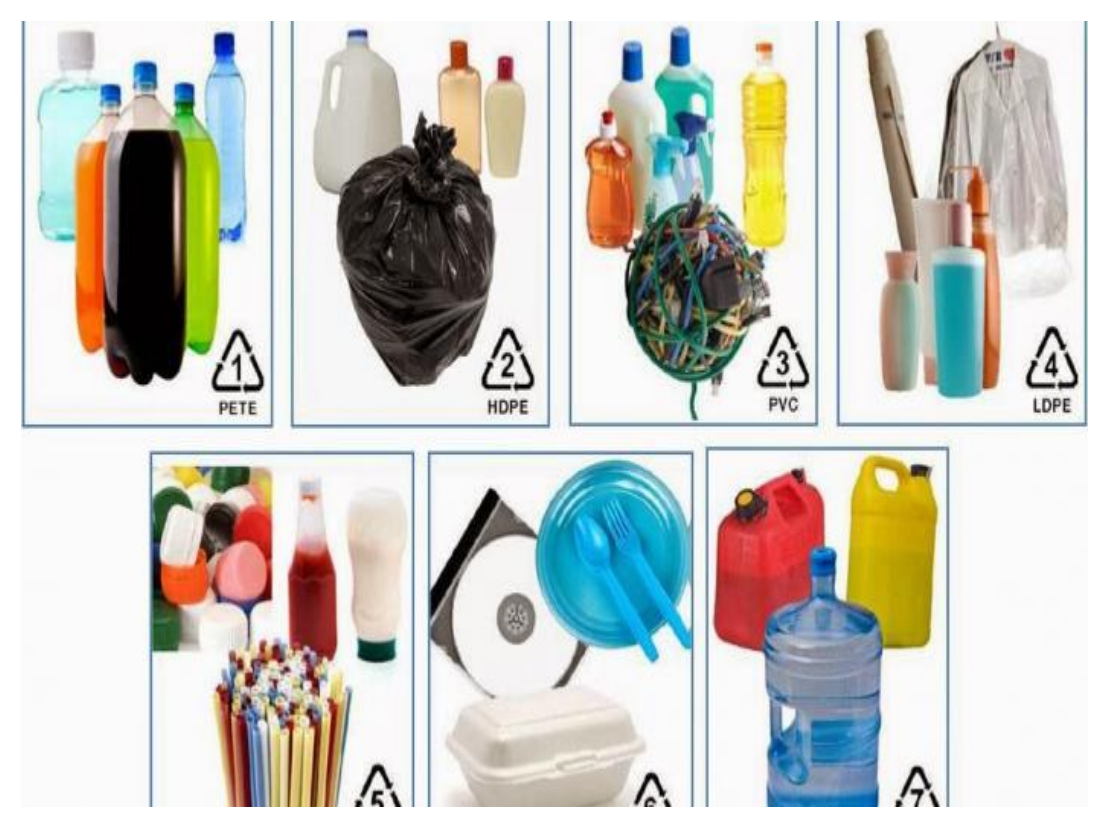

Gambar 1. Jenis-jenis sampah plastik

Kepedulian terhadap sampah, terutama sampah plastik serta pengelolaan sampah menjadi mutlak diperlukan mengingat Indonesia menjadi negara penyumbang sampah plastik terbesar kedua di dunia setelah Cina sebanyak 187,2 juta ton sampah plastik (Wahyuni, 2016). Olehnya itu, perlu dilakukan upaya pengenalan sampah plastik sejak dini melalui pembiasaan terhadap perilaku hidup bersih dan sehat sejak dini melalui pemilahan sampah terhadap siswa sekolah dan 
pra sekolah (Choirul \& Wahyu, 2017). Serta bagi siswa sekolah yang ada di wilayah Sorong Raya mengingat Kota Sorong oleh Tim Adipura masuk dalam 9 (Sembilan) kota terkotor di Indonesia untuk kategori kota sedang yang penilaiannya meliputi penilaian fisik dan tempat pemrosesan akhir (TPA) (detiknews, 2019).

Pada pengembangan dewasa ini, sekolah mengarahkan konsep pendekatan antara siswa dengan lingkungan melalui model Green school. Green school yang disebut adiwiyata adalah salah satu program kementerian negara lingkungan hidup dalam rangka mendorong terciptanya pengetahuan dan kesadaran warga sekolah dalam pelestarian lingkungan hidup yang dalam program ini diharapkan semua warga sekolah ikut terlibat dalam kegiatan sekolah menuju llingkungan yang sehat dan menghindari dampak lingkungan yang negatif (Kementerian Negara Lingkungan Hidup, 2009).

Permasalahan yang sering dialami oleh lingkungan sekolah adalah konsep pembelajaran pendidikan lingkungan hidup masih sebatas teori sehingga perlu didorong semangat siswa agar termotivasi yang ditunjukkan oleh siswa sekolah di Kelurahan Malagusa, Kabupaten Sorong (Akib, Irnawati, \& Ibrahim, (a), 2019). Hal ini perlu dijaga keberlanjutannya agar pemberian pemahaman akan kecintaan terhadap lingkungan hidup serta ekosistem perairan dapat terbentuk sejak dini dan dimulai dari bangku sekolah.

Tujuan pelaksanaan pengabdian kepada siswa sekolah adalah untuk memberikan pemahaman dan pengetahuan kepada siswa tentang pentingnya menjaga kelestarian lingkungan dalam hal pemberian pemahaman tentang sampah, jenis-jenis sampah, dampak sampah terhadap lingkungan dan lingkugan perairan serta menanamkan kepedulian sejak dini kepada siswa-siswa.

Pengabdian ini berbeda dengan pengabdian yang dilakukan oleh (Radhiansyah, Wijanarko, \& Annas, 2019). Pengabdian bagi masyarakat Kota Bogor masyarakat yang terdiri dari Komunitas yang bergerak di bidang lingkungan khususnya terkait sampah plastik (Bogor Clean Action) dan Pelajar Sekolah Menengah Atas di Kota Bogor dalam pengurangan sampah plastic melalui program Bogor Tanpa Kantong Plastik (BOTAK). (Fauzi, et al., 2019) Pengabdian bagi masyarakat Kampung Sungai Kayu Ara. Pengabdian ini 
bertujuan untuk memberikan pengetahuan kepada masyarakat di Kampung Sungai Kayu Ara Kecamatan Sungai Apit Kabupaten Siak tentang bahaya pencemaran limbah plastik pada sungai dan laut diperlukan kegiatan edukasi.

\section{Metode Pelaksanaan}

Metode pelaksanaan yang digunakan adalah metode ceramah dan presentasi yang dilanjutkan dengan kuis interaktif bersama siswa Siswa SMA/SMK dan SMP di Kelurahan Malagusa Distrik Aimas Kabupaten Sorong" di aula SMA Negeri 2 Kabupaten Sorong. Teknik pelaksanaan kegiatan meliputi penyampaian materi secara langsung yang dilanjutkan dengan sesi tanya jawab bersama para siswa.

Metode yang digunakan adalah metode ceramah, tanya jawab dan demonstrasi bersama siswa SMA/SMK dan SMP di Kelurahan Malagusa Distrik Aimas Kabupaten Sorong. Hasil pelaksanaan pengabdian ini bahwa siswa sekolah yang ada di Kelurahan Malagusa, Aimas, Kabupaten Sorong dapat mengetahui tentang sampah, sampah plastic. jenis-jenis sampah plastik, ekosistem perairan, pencemaran lingkungan, klasifikasi pencemaran, baku mutu air, dampak dan mekanisme pencemaran, akibat pencemaran, penanggulanan sampah plastic, serta diharapkan dengan adanya pelatihan ini berdampak pada pengembangan pemahaman dan kemampuan siswa dalam membuang sampah ke tempat sampah atau minimal tidak membuang ke saluran air, sungai, laut atau secara umum ekosistem perairan.

\section{Hasil dan Pembahasan}

Hasil kegiatan ini adalah (1) apresiasi yang tinggi pemerintah setempat dalam hal ini pemerintah kelurahaan Malagusa mengenai kegiatan seminar yang dilaksanakan (2) motivasi tinggi peserta seminar pengabdian yang berasal dari siswa SMK, SMA, dan SMP se-kelurahan Malagusa dengan keaktifan bertanya pada sesi diskusi yang dipandu oleh panitia pelaksana kegiatan. (3) peningkatan pemahaman, pengetahuan dan kemampuan siswa dalam memahami tentang sampah dan dampak sampah bagi lingkungan perairan. Hal ini sejalan dengan bertambahnya kesadaran siswa yang berasal dari faktor individu ditandai dengan 
ketertarikan terhadap materi seminar, sehingga melahirkan kemampuan dalam menerima informasi (Akib \& Ohorella (b), 2019) utamanya pada saat sesi Tanya jawab seminar.

\section{SIMPULAN DAN IMPLIKASI}

Adapun simpulan yang dapat ditarik setelah pelaksanaan PKM ini adalah sebagai berikut: (1) Kegiatan seminar PKM berjalan dengan baik, lancar dan memperoleh apresiasi yang tinggi dari pemerintah setempat, serta pihak sekolah. (2) Kegiatan seminar PKM yang disajikan dalam bentuk ceramah dan dilanjutkan dengan sesi diskusi/Tanya-jawab ini mampu meningkatkan motivasi dan kesadaran siswasiswa yang bersekolah di Kelurahan Malagusa; dan (3) Kegiatan seminar PKM yang telah diselenggarakan dapat meningkatkan pemahaman, pengetahuan, kesadaran dan wawasan bagi siswa-siswa sekolah di Kelurahan Malagusa.

\section{Ucapan Terima kasih}

Ucapan terima kasih penulis haturkan pada Kelompok K2N Mahasiswa Kelurahan Malagusa dan Dosen Pembimbing yang turut serta dalam menyukseskan kegiatan pelatihan tersebut sehingga dapat berjalan dengan baik dan lancar.

\section{Daftar Pustaka}

Akib, M., \& Ohorella, H. M. (2019). Investigating Students' Ability to Use Gerund and Present Participle at English Education Departement of Sorong Muhammadiyah University. Qalam: Jurnal Ilmu Kependidikan, 7(1), 45-55.

Akib, M., Irnawati, I., \& Ibrahim, I. (2019). Seminar Greenschool: Sekolah Peduli Llingkungan Hijau Untuk Siswa SMA/SMK dan SMP. Abdimas: Papua Journal of Community Services, 1(2), 1-5.

Bisnis.com. (2019, Februari 21). Timbulan Sampah Nasional Capai 64 Juta Ton Per Tahun. Dipetik 1 9, 2020, dari Bisnis.com: https://www.google.com/amp/s/m.bisnis.com/amp/read/20190221/99/8916 11/timbulan-sampah-nasional-capai-64-juta-ton-per-tahun 
Choirul, A., \& Wahyu, W. (2017). Pendampingan Pembelajaran Memilah Dan Menempatkan Sampah Pada Tempatnya Sejak Usia Dini Di TK Imbas 1. International Journal Of Community Services Learning, 1(3), 121-126.

Dahruji, D., Wiliniarti, P. F., \& Hendarto, T. T. (2016). Studi Pengolahan Limhbah Usaha Mandiri Rumah Tangga dan Dampak Bagi Kesehatan di Wilayah Kenjeran, Surabaya. Aksiologiya: Jurnal Pengabdian Kepada Masyarakat, 1 (1), 36-44.

Darilaut.id.

(2019,

Juli

2).

https://www.google.com/amp/s/darilaut.id/berita/seekor-dugong-mati-

terdampar-di-sorong/amp. Dipetik 1 8, 2020, dari darilaut.id: https://www.google.com/amp/s/darilaut.id/berita/seekor-dugong-matiterdampar-di-sorong/amp

detiknews. (2019, Januari 14). KLHK Ungkap Kota-kota Terkotor di Indonesia, Mana Saja? Dipetik 1 8, 2020, dari detiknews: https://m.detik.com/news/berita/d-4384000/klhk-ungkap-kota-kotaterkotor-di-indonesia-mana-saja

Direktorat Konservasi Kawasan dan Jenis Ikan, D. K. (2012). Panduan Penanganan Mamalia Laut Terdampar. Jakarta: Direktorat Konservasi Kawasan dan Jenis Ikan, Ditjen KP3K.

Fauzi, M., Efizon, D., Sumiarsih, E., Windarti, W., Rusliadi, R., Putra, I., et al. (2019). Pengenalan dan Pemahaman Bahaya Pencemaran Limbah Plastik pada Perairan di Kampung Sungai Kayu Ara Kabupaten Siak. Seminar Nasional Pemberdayaan Masyarakat, Pekanbaru, 2019-08-21. Unri Conference Series: Community Engagement. Volume 1 (hal. 341-36). Pekanbaru: Unri Conference Series.

Kementerian Negara Lingkungan Hidup. (2009). Panduan Adiwiyata: Wujudkan Sekolah Peduli dan Berbudaya Llingkungan. Jakarta: Kementerian Negara Lingkungan Hidup.

Kurniastuti, N. (2016). Bahaya Plastik Terhadap Kesehatan dan Lingkungan. Forum Teknologi, Vol 3 (1), 6-14.

liputan6.com. (2019, April 3). liputan6.com. Dipetik 1 8, 2020, dari Liputan 6: https://m.liputan6.com/global/read/3933006/sedih-paus-bunting-matiakibat-telan-22-kilogram-sampah-plastik

Nontji, A. (2007). Laut Nusantara. Jakarta : Djambatan. 
Radhiansyah, E., Wijanarko, A., \& Annas, F. B. (2019). Program Kemitraan Telusur Lebak Pilar dalam Mendukung Pengurangan Sampah Plastik di Kota Bogor. Journal of Servite, Volume 1 (1), 1-11.

Wahyuni, T. (2016, Februari 23). Indonesia Penyumbang Sampah Plastik Terbesar Ke-dua Dunia. Dipetik 1 8, 2020, dari CNN Indonesia: https://m.cnnindonesia.com/gaya-hidup/20160222182308-277-

112685/indonesia-penyumbang-sampah-plastik-terbesar-ke-dua-dunia 